\title{
Call to Action on Herbicide Resistance Management
}

\author{
Harold D. Coble and Jill Schroeder*
}

\begin{abstract}
Management of herbicide resistance can be most effectively accomplished if every person and organization involved in agricultural production takes an ownership position and participates in solving the growing problem of weed resistance to herbicides. Growers and other pest management practitioners are keys to effective herbicide resistance management since they make the final decisions on practices used. However, many other people and organizations have an important role to play as well. Agricultural input supply networks, including chemical companies, are a widely used information source for growers' decisions through company marketing efforts. Government agencies may influence decisions through regulations or incentive programs. University scientists through their research, education, and outreach programs may impact management decisions, and organizations such as professional societies, farm and commodity groups, public interest organizations, and the agricultural press play roles as well. It is critically important that all of these groups impacting herbicide resistance management decisions are sending the same message and that message is based on sound science. The time to act is now.
\end{abstract}

Key words: Agricultural community, best management practice, evolved resistance, mechanism of action, selection pressure.

Weed populations change, sometimes rapidly, in response to pressures exerted on them by human endeavors. When plants were first domesticated for agricultural purposes, native plant populations began changing as mankind began to select for certain plants that were more desirable as food sources and weeds began to interfere with production of the desired species. Weed population changes are no doubt happening more frequently today because agriculture is changing more rapidly. Clearly some of the most easily recognizable selection pressures today come from management practices utilized by modern agriculture, such as herbicide use. Herbicides are not the only selection pressure exerted by modern agriculture. Tillage or lack thereof, fertilization practices, crop selection and rotation, and irrigation practices, among other factors, can result in weed community changes (Ball and Miller 1990). However, herbicide use probably results in more rapid changes than that caused by some of the other practices, and for the most part herbicide resistance is more easily observable. The effect of weed resistance is often dramatically observed in the field.

Herbicide resistance is not a new phenomenon, but it is clearly becoming more prevalent and is now

\footnotetext{
DOI: $10.1614 / W S-D-15-00032.1$

* Professor Emeritus, Crop Science Department, North Carolina State University, Raleigh, NC 27695; Agronomist, U.S. Department of Agriculture Office of Pest Management Policy, Washington, DC 20250. Corresponding author's Email: Harold.coble@earthlink.net
}

widespread all over the world. In 2015, there were 244 species of weeds with evolved resistance to 22 of the 25 known herbicide sites of action (156 different herbicides) in 85 crops in 66 countries worldwide (Heap 2015). With no new chemical site of action herbicide development over the past $20 \mathrm{yr}$, weed resistance is a clear and present danger to the successful practice of crop production as it is known today. In the relatively recent past (ca. 1960 to 1990) the solution to weed resistance was to switch to a different herbicide to which the weed in question was not resistant. With no new site of action chemistry on the horizon, options for this type of technical solution are quickly running out. Even the new stacked herbicide-trait technologies on the near horizon that are being touted as solutions to resistant weed problems depend on use of herbicides to which there are already known resistant weeds.

Garrett Hardin (1968), in "The Tragedy of the Commons," makes the case that some problems have no technical solutions. He defines a technical solution as "one that requires a change only in the techniques of the natural sciences, demanding little or nothing in the way of change in human values or ideas of morality." Weed scientists are most familiar with technical solutions in weed management, since that is what they typically do. For the most part weed scientists have been very successful in developing technical solutions to the problem of weeds, such as spraying herbicides to kill weeds. Weed scientists must have been successful in the 
growers' minds because nearly $100 \%$ of cropland acres in the United States are treated with herbicides for weed control annually. And it is clear that no technological solution exists today that even approaches the effectiveness, efficiency, and economics of using herbicides to kill weeds. Also, in the perhaps limited view of the authors, there is nothing in the near future to change that.

In "The Tragedy of the Commons," the term commons refers to some resource available to all members of a class or society. In this respect, susceptibility of weeds to herbicides might be considered a commons resource. The tragedy of the commons lies in the depletion of shared resources by individuals who act in their own selfinterest despite the advantage to society of preservation of such resources. Thus, depletion of weed susceptibility to herbicides is a tragedy, and single reliance on individual herbicide-based solutions have proven to be limited in their efficacy and effectiveness over time.

So, what solutions are available for herbicide resistance? A necessity for success in weed resistance management is a mindset change on the part of growers and those who advise them (National Academy of Science National Research Council 2012). Advisors include a broad range of people from university and government scientists and extension workers to consultants, dealers, distributors, and others in the supply chain. A mindset change in this regard is not a change from one technology to another. It is a change in the approach to decision making relative to the commons. If a mindset change is necessary to avoid this tragedy of the commons, assuming there is still time, the mindset change requires a change in human values. Surely there will be technical issues involved in weed control, but the mindset change is not a weed control issue-it is a social issue. And who better to guide this social issue than the social scientists who are familiar with agriculture? It is not enough to just bring the social scientists "into the fold" with weed scientists. They should play a leading role in the effort. Weed scientists have a role developing best management practices (BMPs), but the BMPs alone will not save the commons. The change in mindset needed to embrace the BMPs is the key, and because so many weed species in so many areas of the world have developed resistance to so many herbicides, the time for action is now. This call to action on herbicide resistance management will address the roles of various individuals and groups in the effort.

\section{Roles in Herbicide Resistance Management-The Call to Action}

Agricultural Producers and Other Practitioners. Although most of this section will address agricultural producers, it is recognized that herbicide resistance management decisions are also made by managers of aquatic resources, forestry managers, right-of-way managers, and others, and that many times these environments overlap with agricultural environments. No one group is impacted by weed resistance as much as farmers, so no one has as much to gain by making the right decisions as farmers. The final decision on production practice choices lies with farmers, but they do not operate in a vacuum. They influence their neighbors by the decisions they make and their neighbors, sometimes even those some distance away, influence them as well. Herbicide resistance is everyone's problem, not just that of neighbors, so everyone is involved in solutions. Also, most farmers do not want regulatory agencies telling them what weed control tools they can use where or when.

The call to action for farmers involves four objectives. First, farmers must educate themselves with an understanding of the causes of herbicide resistance and the types of strategic approaches that will help avoid the increase in resistance in the future. Second, choosing valid information sources is critical to success, making sure the information relied upon for decision making is based on sound science and experience and is appropriate for local conditions. Third, attention to what is happening in fields, particularly after herbicide applications, is critical. Recent glyphosate-resistant crop technologies were so successful at controlling weeds that routine scouting to assess weed control needs decreased. Herbicide resistance does not happen overnight. Identifying the first occurrence in a field is critical and the only way to do that is to monitor for treatment effectiveness and properly address any weeds that escape treatment. Fourth, a long-term view of operations is important to the success of herbicide resistance management. It is clear that field-by-field weed management plans that include a diversity of approaches are necessary over years to maintain the susceptibility of weed populations to herbicides.

It may be time that farmers organize community groups with the purpose of getting serious about weed resistance management. There are examples of such groups already, and they are most effective when organized by growers who make their own decisions based on their knowledge of conditions and cropping systems (Ervin and Jussaume 2014). 
The objective would be for the entire community to come up with plans for long-term resistance management strategies. Every grower may not need or be able to use the same tactics, because there is almost always more than one BMP, but everyone would be committed to an overall strategy aimed at long-term resistance management. Advice can be provided from extension personnel or consultants and then farmers decide what approaches they need to follow and what practices they need to use. This approach may be the best effort to avoid government regulations aimed at weed resistance management. There is a great need to show that collective grower-advisor efforts can work to stem the tide of weed resistance and make farming as sustainable as possible.

Agricultural Input Supply Network. The agricultural input supply network includes agricultural chemical, seed, and equipment companies; the distribution chain; and the retail outlets that supply those products to growers. That network is often the final and most influential source of weed management information for growers in terms of products used (Givens et al. 2011; Johnson et al. 2009). The network members, therefore, must be challenged to consider how providing current, credible, scientifically sound, and nonbiased information to their grower clients can be included in and enhance their business plan.

Next to farmers, individual companies in the input supply network have the most to lose from herbicide resistance-their markets. Chemical and seed companies have developed and marketed excellent technology for managing weeds in a variety of situations, and that has helped create the most efficacious weed control programs in history. Clearly, there are many cropping systems where that technology has not been adequately integrated with other weed management tools, thus leading to the resistance problem growers have today. There are some new technologies and some new uses of older technologies under development. Hopefully, marketing groups have learned by now that no tool can be used on every field every year without unintended consequences, such as selection for resistant weed populations. Chemical and seed marketing groups, probably more than any other member of the community, have the opportunity to provide leadership in resistance management through creative marketing programs that integrate a variety of weed management tools at the farm level. Companies should cooperate among themselves to encourage an industry-wide effort in providing education and training, as well as individually offer incentives to promote proper utilization of their technologies and to reward stewardship. Several chemical companies are presently offering incentives to growers to include, in addition to their own chemistry, a second mechanism-of-action (MOA) herbicide in weed control programs. That approach is a good BMP as long as resistance is not already present. However, if resistance is already present, adding a second MOA does not provide more than one MOA on the resistant species, and continued use of such a program only sets the stage for additional resistance development in the future. Additional herbicide use cannot be the only approach to resistance management over the long term.

The distribution and retail network usually has the last opportunity to influence grower decisions on product use in weed control programs. That unique position requires continual education about technology issues and frequent monitoring of local pest conditions in order to be a valid resource. Retail outlets should maintain a relationship with a variety of chemical and seed suppliers to ensure access to the variety of products and inventory necessary to serve clients' needs related to managing resistance.

Public-Sector Weed Scientists. University and government research and outreach groups have been critical components of the development and implementation of remedies for herbicide resistance. In spite of the important work done by these groups, there is still a growing herbicide resistance problem. Clearly the message on resistance management is not being delivered effectively everywhere, because for some reason many growers are not managing resistance. Perhaps it is time to call on social science colleagues to help with crafting the message and getting it out. Maybe more consideration of what impacts grower decisions, particularly from the economic perspective, is appropriate. And, importantly, that message needs to be in terms easily understood by clientele. One of the critical capabilities of scientists in the public sector is the opportunity to think "outside the box" in developing new approaches. Growers are urged to include nonchemical tactics of weed control in their farm operations, but too often little direction is offered on how to integrate these tactics into their weed control programs. The time is now for public-sector scientists to explore new avenues of nonchemical weed control tactics and how to incorporate these tactics into existing farm practices with some creative thinking. 
A second important role of public-sector scientists is in the education of the next generation of weed scientists. It is critical that these students are educated and gain experience in both the basic and applied aspects of weed science. In addition, course work in the social sciences would provide students with the background needed to effectively communicate and would familiarize them with how to network with social scientists to implement creative approaches in weed management communication.

Fee-for-Service Advisors. A number of independent consultants operate in a fee-for-service capacity to provide advice to growers on weed management practices. Many of these consultants operate over large acreages and different agricultural systems. Because these groups provide advice directly to growers, it is imperative that they stay current on the latest technology performance characteristics and are aware of trends in their area related to pest resistance issues. Growers need assistance from consultants to develop long-term, field-by-field management plans that work for their individual situations. Growers have also indicated that professional certification and the independence of crop consultants is important. Finally, consultants need to play an important role in education and training of future generations of consultants. University education is a starting point for future consultants, but nothing substitutes for in field training to prepare for a career as a consultant.

Federal Government Agencies. U.S. Department of Agriculture (USDA) Agriculture Research Service (ARS). ARS needs to continue to invest in basic and applied research in weed science. In addition to these research programs, ARS has conducted some very successful area-wide pest management programs in the past based on field-ready research programs (Prosser et al. 2002; Smith and Sheley 2012). A number of research programs, both in and outside ARS, are ready for area-wide implementation. Demonstration of the effectiveness of pest management programs in unique areas could be an important step in improved resistance management on a wider scale. The experience of ARS is important for leading effective area-wide program organization. There are many potential areas to choose from for such a program, and it would be an important way to demonstrate the effectiveness of such an approach.

USDA Animal and Plant Health Inspection Service (APHIS). APHIS does an excellent job of protecting agricultural systems from new pests arriving in the United States from foreign locations. However, the agency must continue to invest in these programs and consider how they might help address resistance issues. In some ways, weed species that have evolved resistance may be considered new pests. These species are genetically different from the susceptible genotypes, even though they may look very much the same and may be called the same species. Unless there is some restricted authority within APHIS, the agency should consider treating the initial occurrence of a herbicide-resistant weed species as a new pest, and using all tools available to keep those infestations from becoming established and reduce their movement across state and national borders.

USDA National Institute for Food and Agriculture (NIFA). NIFA funds research and extension efforts in agricultural production at land-grant universities and other institutions. Recently, some research funding has been made available for herbicide resistance efforts. A serious commitment of federal research funding is very important in the quest to understand the evolution and spread of herbicide resistance, to understand the biology and ecology of these driver species, and, based on this understanding, to develop new ways of managing weed resistance and getting information out to growers and others in the business of agricultural production. Funding is not a one-time need, and needs to be continued. In addition, NIFA would benefit from having a trained weed scientist in a national program leader position within the agency.

USDA Economic Research Service (ERS). The economics of herbicide resistance management, particularly multi-year program economics, is a critical component of grower decision making. The ERS is in a position to lead the efforts in development of this important information. Some good economic information on the profitability of resistance management programs over the long term is already available within ERS. Publication of that information in a clear, reader-friendly format and subsequent widespread utilization is critical to the success of resistance management at the farm level.

USDA Natural Resources Conservation Service (NRCS). NRCS has programs that serve as incentives to help growers get started with resistance management programs. Many of those programs are aimed at soil and water conservation through limited tillage. However, the presence of herbicide-resistant weeds can cause growers to discontinue those conservation programs because of a need to manage those populations with tillage. Resistance management will help preserve these important 
conservation efforts. NRCS is urged to allow enough flexibility in their conservation programs for growers to develop effective resistance management programs that include diverse management yet adhere to the long-term conservation goal. In addition, the secretary of agriculture issued a news release on October 15,2014, indicating that both NRCS and APHIS would be working actively to promote herbicide resistance management through their individual agency programs (USDA 2014).

USDA Risk Management Agency (RMA). Herbicide resistance adds another risk for agricultural production today. RMA has the ability to help manage that risk through programs such as crop insurance that might be used to provide incentives for growers. The call to action for RMA is to hold discussions with other agricultural agencies and with farm groups to determine the best way to become involved in helping to manage the great agricultural risk of herbicide resistance.

USDA Office of Pest Management Policy (OPMP). OPMP was established with the mandate to integrate USDA's activities related to pest management (for additional information see http://www. ars.usda.gov/Research/docs.htm?docid=12430). In addition, the secretary's news release of October 15, 2014, designated OPMP as the lead in USDA's activities on herbicide resistance. The call to action for OPMP is to coordinate and communicate across agencies to make sure that all agencies are involved where appropriate in helping get herbicide resistance under control.

Environmental Protection Agency (EPA). EPA has a difficult job in balancing environmental protection with making available the necessary tools for agricultural production. The agency has recently made the decision to include additional herbicideresistance information on product labels, but the job is not done (EPA 2014). Requiring a program for monitoring, reporting, and mitigating new cases of resistance is an interesting new approach to helping with management. EPA is encouraged to carefully craft, develop, and monitor the effectiveness of this new program and modify the program if needed, and expand the program only as success is documented. The agency is also urged to continue communicating with all institutions involved to make sure appropriate regulatory oversight helps sustain the tools necessary for protecting the agricultural enterprise.

Farm Organizations and Crop Commodity Groups. Farm organizations and crop commodity groups represent farmer concerns in many areas and have a stake in making resistance management work, not only for the commodity they represent, but for all of agriculture. These groups have great influence on a broad audience, including legislators and agricultural agencies. These groups should form strategic alliances among organizations to have an even greater impact at the regional and national level in promoting research, outreach, and education related to resistance management, because a unified voice is strongest.

Public Interest Groups. Input from public interest groups is important to the weed management community. These groups sometimes bring insight to bear on issues that is not heard elsewhere. The call to action for public interest groups is to continue a scientifically informed and civil discussion of all the issues involved in resistance management and to work together with others in the community toward improvement of weed management programs, including being advocates for good stewardship.

Professional Societies. Professional societies represent a focal point in providing organization of community action and have the ability to make sure appropriate information is available on resistance management for decision makers. These societies provide a forum for a diversity of opinions to be heard and debated in the formation of resistance management strategies. Professional societies also represent the most likely place for the development and implementation of certification programs for various specializations.

Agricultural Press. The agricultural press has done an outstanding job of getting the word out on herbicide resistance, and it is an impressive story to tell. The agricultural press serves a critical role in the community by providing information from a variety of sources that helps farmers make decisions and become aware of trends in similar agricultural settings. The call to action is to keep up the good work and continue to pursue those scientifically sound and accountable stories that can help the farm community with the educational process. It will be important to document success stories to assist growers still looking for success in their management efforts.

\section{Conclusion}

What happens if there is not a change in the way weed management decisions are made and resis-

Coble and Schroeder: Call to action on herbicide resistance management -665 
tance continues to spread? Within most societies, rules and regulations are the basis for saving the commons because some people will only act in their own self-interest under the guise of "freedom." Could herbicide resistance management be regulated? Maybe, but prescriptive regulation of herbicide use may not be feasible, necessary, or in the best interest of agriculture at this time. Such a regulatory system most likely would be cumbersome and ineffective, very expensive, take years to develop and implement, and probably impossible to enforce. There is a need to give society a chance before going down that road. There certainly are regulations that can help growers and their advisors with the right approach to resistance management decisions, and those should be implemented. For example, herbicide labels should specify mechanism(s) of action and reference BMP resources and other nonprescriptive approaches that may help with proper technical decisions. Some companies are already doing a good job of this on their labels, and all labels should come into conformance.

There is an opportunity before the agricultural community today, perhaps the opportunity of a lifetime, to work together to conquer the herbicide resistance problem. But, it has been said that to take advantage of the opportunity of a lifetime, one must act during the lifetime of the opportunity. The opportunity to get control of herbicide resistance most likely has a limited lifetime because of the rapidly expanding cases of resistance and the limited herbicide resources available. So, before it is too late, the entire agricultural community must get to work TODAY!

Every agricultural sector has a role to play and every agricultural sector must be accountable in providing solutions for the entire community.

\section{Acknowledgments}

Dr. Schroeder contributed to this article in her personal capacity. The views expressed are her own and do not necessarily represent the views of the U.S. Department of Agriculture or the U.S. government.

\section{Literature Cited}

Ball DA, Miller SD (1990) Weed seed population response to tillage and herbicide use in three irrigated cropping sequences. Weed Sci 38:511-517

[EPA] Environmental Protection Agency (2014) EPA Announces Final Decision to Register Enlist Duo, Herbicide Containing 2, 4-D and Glyphosate/Risk Assessment Ensures Protection of Human Health, including Infants, Children. http://yosemite.epa.gov/opa/admpress.nsf/ bd 4379 a 92 cecee ac 8525735900400 c 27 / 72 fde554930f3f6985257d7200591180! OpenDocument. Accessed July 8, 2015

Ervin D, Jussaume R (2014) Herbicide resistance: integrating social science into understanding and managing weed resistance and associated environmental impacts. Weed Sci 62:403-414

Givens W, Shaw DR, Neuman ME, Weller SC, Young BG, Wilson RG, Owen MDK, Jordan DL (2011) Benchmark study on glyphosate-resistant cropping systems in the United States. Part 3: grower awareness, information sources, experiences and management practices regarding glyphosateresistant weeds. Pest Manag Sci 67:758-770

Hardin G (1968) The tragedy of the commons. Science 162:1243-1248

Heap I (2015) International Survey of Herbicide Resistant Weeds. http://weedscience.com/summary/home.aspx. Accessed July 8, 2015

Johnson WG, Owen MDK, Kruger GR, Young BG, Shaw DR, Wilson RG, Wilcut JW, Jordon DL, Weller SC (2009) U. S. Farmer awareness of glyphosate-resistant weeds and resistance management strategies. Weed Technol 23:308-312

National Academy of Science National Research Council (2012) Weed Resistance Summit. http://nas-sites.org/ hr-weeds-summit/. Accessed February 5, 2015

Prosser CW, Anderson GL, Wendel LE, Richard RD, Redlin BR (2002) TEAM leafy spurge: an areawide pest management program. Integrated Pest Manag Rev 7:47-62

Smith B, Sheley RL (2012) Government success in partnerships: the USDA-ARS areawide ecologically based invasive annual grass management program. Rangelands 34:17-24

[USDA] U.S. Department of Agriculture (2014) USDA Announces Measures to Help Farmers Diversify Weed Control Efforts. Secretary Vilsack Press Release October 15, 2014. http://www.usda.gov/wps/portal/usda/usdahome? contentid $=2014 / 10 / 0227 . x m l \& c o n t e n t i d o n l y=$ true. Accessed February 23, 2015

Received February 26, 2015, and approved July 21, 2015.

Associate Editor for this paper: Sarah Ward, Colorado State University. 